\title{
Prevalence of anxiety and depression disorder and associated factors during postpartum in puerperal women
}

Erildo Vicente Muller 1

iD https://orcid.org/0000-0003-4643-056X

Camila Marinelli Martins 2

(iD) https://orcid.org/0000-0002-8425-5769

Pollyanna Kássia de Oliveira Borges 3

D https://orcid.org/0000-0002-9390-0459

1-3 Departamento de Saúde Pública. Universidade Estadual de Ponta Grossa. Campus Uvaranas. Rua Luiz Nadal Motti. Ponta Grossa, PR, Brasil. CEP: 84.030-900. E-mail: erildomuller@hotmail.com

\begin{abstract}
Objectives: to check the prevalence of anxiety and depression disorder and associated factors during the postpartum period in puerperal women in the city of Ponta Grossa, Paraná.

Methods: cross-sectional study conducted in an outpatient clinic for newborn care in the city of Ponta Grossa, Paraná, Brazil, in 2016 and 2017. 250 puerperal women were evaluated with the application of a form to collect anxiety/depression, socioeconomic and gestational data. Descriptive and multiple correspondence analyses were performed.

Results: most puerperal women (81.2\%) had no depression or a mild depression, $14.4 \%$ with mild to moderate depression and $4.4 \%$ with moderate to severe depression. In relation to anxiety, $68.4 \%$ presented a minimum degree, $21.6 \%$ mild anxiety, $7.6 \%$ moderate anxiety and $2.4 \%$ severe anxiety. Concerning the associated factors with postpartum depression, no sociodemographic variables or those related to childbirth were associated. As for anxiety, yellow/indigenous skin color, lack of paternal support and having interrupted pregnancy were associated with more advanced anxiety conditions.

Conclusion: there was no association between demographic and health conditions with postpartum depression; however, regarding anxiety, the yellow/indigenous skin color, the lack of paternal support and the interruption of previous pregnancies were associated with more advanced anxiety conditions.
\end{abstract}

Key words Depression, Anxiety, Pregnant woman, Postpartum period

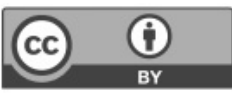




\section{Introduction}

Anxiety disorders and depressive symptoms have increased significantly over time, mainly due to the modern way of life. ${ }^{1}$ Estimates indicate that depression will probably be the second leading cause of morbidity in the world by the year $2020 .^{2}$

Depression is considered a serious public health problem, with a predominance in women, often preceded by significant life events, such as pregnancy, childbirth and the postpartum period. ${ }^{3,4}$

Postpartum depression (PPD) present variations in its occurrence, with a higher prevalence in less developed countries. In Brazil, authors point out that the prevalence of PPD varies between 10 and $15 \%$, and approximately $50 \%$ of the cases are diagnosed.2,5

When a woman becomes pregnant, the advent of the child is usually fraught with expectations, changes and challenges. After the birth, the mother is faced with the real baby, a production of her own and that may be different from what she imagined. Therefore, there is a puerperal woman who tries to balance the tasks assigned to her as a mother (adaptation of home routine, as well as financial, emotional and social issues), along with the hormonal, physical and emotional transformation she is going through. 6

Pregnancy and puerperium need to be viewed with special attention, 6 observing several alterations in the female's behavior and in the couple's life. In these periods, an ideal model of the perfect mother is expected, i.e., a romanticized image of motherhood that is grounded in a rigid standard incapable of admitting any trace of ambivalent feelings that she may feel. ${ }^{7}$ Such demands explain why the risk of developing depression is three times higher in the first month of puerperium, when compared to other periods of a woman's life. 8

Regarding to the symptoms of depression associated with the birth of a baby, they usually start between the fourth and eighth week after childbirth, commonly reaching their maximum intensity in the first six months, being the second cause of illness in women in the world, which may lead to suicide, one of the main mortality factors among women of childbearing age. ${ }^{9}$ The symptoms of postpartum depression are mainly associated with depressed mood, fear, anxiety, discouragement and even self-destructive thoughts or desires in causing harm to the child. ${ }^{9}$ Arrais et al. 10 highlight the existence of three disorders that are characteristics of the puerperal period: motherhood melancholy (baby blues), postpartum depression and puerperal psychosis.
Angelo et al. ${ }^{7}$ describe that depression and anxiety are often mood disorders, usually associated with persistent clinical condition of pain. In this perspective, due to the fear-tension-pain triad that coexist in pregnancy, childbirth and postpartum, where the emotional situation is directly related to muscle and physiological functions, the evolution of depression may then occur in women in the postpartum period.

In light of the foregoing, the objective of this study was to check the prevalence of anxiety and depression disorder and associated factors during the postpartum period in puerperal women in the city of Ponta Grossa, Paraná.

\section{Methods}

This is a cross-sectional and epidemiological study, conducted in an outpatient clinic for newborn care in the city of Ponta Grossa, which has a service that welcomes all puerperal women in the city to apply the first doses of vaccine intended for newborns. Data collection was performed in the period of March 2016 to March 2017.

250 puerperal women (convenience sample) were evaluated with the application of a form to collect anxiety/depression, socioeconomic and gestational data. The inclusion criteria for the research were: women in the puerperium phase with the last pregnancy having occurred on a date equal to or less than four weeks from the date of the application of the questionnaires and the acceptance to participate in the research. The exclusion criteria were: refusing to participate in the research or filling out the forms uncompletely.

Firstly, the objective of the research was explained to all the invited puerperal women, and then they were given the informed consent form. After the acceptance to participate, a questionnaire, prepared by the Authors, was applied to collect socioeconomic data. The variables of interest were: age, schooling, race, religion, employment, child planning and acceptance of pregnancy by the woman, the child's father and the family, marital status, income, number of accomplished prenatal consultations, preference for the child's sex and the child's date of birth.

In order to assess the prevalence of anxiety, we applied the Beck II Anxiety Questionnaire - BAI, Portuguese version, where "minimal anxiety" was characterized when the score varied from 0 to 7 points; "mild anxiety", from 8 to 15 ; "moderate anxiety", from 16 to 25 ; and "severe anxiety", from 26 to 63 points. 
In order to evaluate the incidence of postpartum depression, we used the Beck Depression Questionnaire - BDI II, Portuguese version, composed of 21 questions with different alternatives about how the individual has been feeling recently, with the following outcomes: "no or mild depression", when it scored less than 10 points; "mild to moderate depression", between 10 and 18; "moderate to severe depression", between 19 and 29; and "severe depression", between 30 and 63 points. 11

Initially, we evaluated the relative frequency of the variables according to the BDI classification (no or mild depression, mild to moderate depression, moderate to severe depression and severe depression); and according to the BAI classification (minimum degree of anxiety, mild anxiety, moderate anxiety and severe anxiety). The evaluated variables were: schooling, race, religion, employment, marital status, income, planning, family support, father support, interrupted pregnancy and preference for the child's gender.

After obtaining the relative frequencies, the anxiety and depression profiles were checked with multiple correspondence analysis. Multiple correspondence analysis is an alternative of principal component analysis or factor analysis for qualitative data. Given that the dependent variables (BDI and BAI classifications) are not binary, the use of an alternative to conventional analyses became necessary. In this analysis, the contingency table or crossfrequency table, produced when two or more variables are crossed, is transformed into a matrix with the conditional probabilities of the original values of the table. Accordingly, the final product shows a two-dimensional space defined by the two most important axes of variability of the variables. Thus, the association among variables is checked by means of the proximity of the axes formed by each one, while the intensity of these associations is checked by means of their distance from the origin, assuming that the more distant from the origin, the less random the behavior of the variability of the vector. ${ }^{12}$ Consequently, when distant from the axes and close to each other, the vectors were considered significant and associated.

The analyses were performed in the $\mathrm{R}$ environment (R Core Team, 2017) ${ }^{13}$ and the multiple correspondence analysis with the "ca" package. 14

This study was approved by the Ethics Committee in Research with Human Beings at the Universidade Estadual de Ponta Grossa under opinion number 1.176.598/2015.

\section{Results}

In Table 1, the frequencies of depression in the BDI classification are described according to the study variables. There were no women classified as severe depression, $81.2 \%$ had no or mild depression, $14.4 \%$ mild to moderate depression and $4.4 \%$ moderate to severe depression. Among the frequencies of the sociodemographic variables, $45.2 \%$ of the total had no depression and studied up to high school, $50.0 \%$ were white, $40.2 \%$ were Catholic, $48.8 \%$ were unemployed or looking for a job, $66.8 \%$ were married or in a stable union and $46.0 \%$ had a family income between 1 and 3 minimum wages (Table 1).

Regarding the variables related to pregnancy, also displayed in Table 1, 43.6\% of the total had no depression and childbirth was a cesarean section, $45.2 \%$ had planned their pregnancy, $76.0 \%$ had much family support, $75.6 \%$ had much father support, $80.4 \%$ did not interrupt the pregnancy and $61.6 \%$ had no preference of the child's sex (Table 1).

In Table 2 displays the study variables according to the BAI classification. The highest frequency was minimal degree of anxiety, with $68.4 \%$, followed by $21.6 \%$ mild anxiety, $7.6 \%$ moderate anxiety and $2.4 \%$ severe anxiety. Among the frequencies of sociodemographic variables, $36.8 \%$ of the total were in minimum degree of anxiety and studied up to high school, $40.0 \%$ were white, $34.5 \%$ were Catholic, $39.2 \%$ were unemployed or looking for a job, $56.4 \%$ were married or in a stable union and $39.2 \%$ had a family income between 1 and 3 minimum wages (Table 2).

In regards to the variables related to pregnancy, also displayed in Table 2, 33.2\% of the total were in a minimum degree of anxiety and childbirth was via vaginal, $39.6 \%$ had planned their pregnancy, $64.0 \%$ had much family support, $63.2 \% \%$ had much father support, $68.0 \%$ did not interrupt pregnancyand $50.0 \%$ had no preference of the child's sex (Table 2).

Figures 1 and 2 display the multiple correspondence analyses according to the BDI (Figure 1) and BAI (Figure 2) classifications. There was no significant association profile between depression and the sociodemographic variables or those related to childbirth. As displayed in Figure 1, the main vectors (BDI_1 = no or mild depression, BDI_2 = mild to moderate depression and BDI_3 = moderate to severe depression) were not close to other variables and/or distant from the axes.

As for anxiety, we can infer that there was a significant association between moderate anxiety and yellow/indigenous race in the evaluation of the sociodemographic variables. There was a significant 
Table 1

Frequency of depression in puerperal women in the BDI classification, according to sociodemographic and health conditions. Ponta Grossa, Paraná; 2017.

\begin{tabular}{|c|c|c|c|c|c|c|}
\hline \multirow[t]{2}{*}{ BDI - classification } & \multicolumn{2}{|c|}{$\begin{array}{l}\text { No or mild } \\
\text { depression }\end{array}$} & \multicolumn{2}{|c|}{$\begin{array}{l}\text { Mild to moderate } \\
\text { depression }\end{array}$} & \multicolumn{2}{|c|}{$\begin{array}{c}\text { Moderate to severe } \\
\text { depression }\end{array}$} \\
\hline & $\mathrm{n}$ & $\%$ & $\mathrm{n}$ & $\%$ & $\mathrm{n}$ & $\%$ \\
\hline \multicolumn{7}{|l|}{ Schooling } \\
\hline Did not attend school & - & - & - & - & - & - \\
\hline Elementary school & 47 & 18.8 & 14 & 5.6 & 5 & 2.0 \\
\hline High school & 113 & 45.2 & 16 & 6.4 & 5 & 2.0 \\
\hline Higher education & 43 & 17.2 & 6 & 2.4 & 1 & 0.4 \\
\hline \multicolumn{7}{|l|}{ Race } \\
\hline White & 125 & 50.0 & 22 & 8.8 & 9 & 3.6 \\
\hline Black or mixed skin color & 77 & 30.8 & 11 & 4.4 & 2 & 0.8 \\
\hline Yellow or indigenous & 1 & 0.4 & 3 & 1.2 & - & - \\
\hline \multicolumn{7}{|l|}{ Religion } \\
\hline Catholic & 100 & 40.2 & 18 & 7.2 & 6 & 2.4 \\
\hline Evangelical & 76 & 30.5 & 17 & 6.8 & 3 & 1.2 \\
\hline Others & 12 & 4.8 & - & - & - & - \\
\hline No religion & 15 & 6.0 & - & - & 2 & 0.8 \\
\hline \multicolumn{7}{|l|}{ Employment } \\
\hline Employed & 81 & 32.4 & 17 & 6.8 & 4 & 1.6 \\
\hline Unemployed or looking for a job & 122 & 48.8 & 19 & 7.6 & 7 & 2.8 \\
\hline Retired & - & - & - & - & - & - \\
\hline \multicolumn{7}{|l|}{ Marital status } \\
\hline Married/stable union & 167 & 66.8 & 30 & 12.0 & 8 & 3.2 \\
\hline Single/divorced & 36 & 14.4 & 6 & 2.4 & 3 & 1.2 \\
\hline Widowed & - & - & - & - & - & - \\
\hline \multicolumn{7}{|l|}{ Family income (minimum wage) } \\
\hline Up to 1 & 48 & 19.2 & 8 & 3.2 & 3 & 1.2 \\
\hline $1-3$ & 115 & 46.0 & 21 & 8.4 & 7 & 2.8 \\
\hline Over 3 & 40 & 16.0 & 7 & 2.8 & 1 & 0.4 \\
\hline \multicolumn{7}{|l|}{ Type of childbirth } \\
\hline Cesarean section & 109 & 43.6 & 18 & 7.2 & 6 & 2.4 \\
\hline Vaginal & 94 & 37.6 & 18 & 7.2 & 5 & 2.0 \\
\hline \multicolumn{7}{|l|}{ Planning } \\
\hline Yes & 113 & 45.2 & 15 & 6.0 & 6 & 2.4 \\
\hline No & 90 & 36.0 & 21 & 8.4 & 5 & 2.0 \\
\hline \multicolumn{7}{|l|}{ Family support } \\
\hline Much support & 190 & 76.0 & 33 & 13.2 & 7 & 2.8 \\
\hline Little support & 13 & 5.2 & 3 & 1.2 & 4 & 1.6 \\
\hline \multicolumn{7}{|l|}{ Father support } \\
\hline Much support & 189 & 75.6 & 33 & 13.2 & 11 & 4.4 \\
\hline Little support & 14 & 5.6 & 3 & 1.2 & - & - \\
\hline \multicolumn{7}{|l|}{ Interrupted pregnancy } \\
\hline Yes & 2 & 0.8 & - & - & - & - \\
\hline No & 201 & 80.4 & 36 & 14.4 & 11 & 4.4 \\
\hline \multicolumn{7}{|l|}{ Preference of the child's sex } \\
\hline Boy & 20 & 8.0 & 8 & 3.2 & - & - \\
\hline Girl & 29 & 11.6 & 10 & 4.0 & - & - \\
\hline No preference & 154 & 61.6 & 18 & 7.2 & 11 & 4.4 \\
\hline Total & 203 & 81.2 & 36 & 14.4 & 11 & 4.4 \\
\hline
\end{tabular}

$\mathrm{BDI}=$ Beck Depression Inventory. 
Table 2

Frequency of anxiety in puerperal women in the BAI classification, according to sociodemographic and health conditions. Ponta Grossa, Paraná; 2017.

\begin{tabular}{|c|c|c|c|c|c|c|c|c|}
\hline \multirow[t]{2}{*}{ BAI - classification } & \multicolumn{2}{|c|}{$\begin{array}{l}\text { Minimum degree } \\
\text { of anxiety }\end{array}$} & \multicolumn{2}{|c|}{ Mild anxiety } & \multicolumn{2}{|c|}{$\begin{array}{c}\text { Moderate } \\
\text { anxiety }\end{array}$} & \multicolumn{2}{|c|}{$\begin{array}{l}\text { Severe } \\
\text { anxiety }\end{array}$} \\
\hline & $\mathrm{n}$ & $\%$ & $\mathrm{n}$ & $\%$ & $\mathrm{n}$ & $\%$ & $\mathrm{n}$ & $\%$ \\
\hline \multicolumn{9}{|l|}{ Schooling } \\
\hline Did not attend school & 43 & 17.2 & 14 & 5.6 & 7 & 2.8 & 2 & 0.8 \\
\hline High school & 92 & 36.8 & 30 & 12.0 & 9 & 3.6 & 3 & 1.2 \\
\hline Higher education & 36 & 14.4 & 10 & 4.0 & 3 & 1.2 & 1 & 0.4 \\
\hline \multicolumn{9}{|l|}{ Race } \\
\hline White & 100 & 40.0 & 39 & 15.6 & 13 & 5.2 & 4 & 1.6 \\
\hline Black or mixed skin color & 69 & 27.6 & 15 & 6.0 & 4 & 1.6 & 2 & 0.8 \\
\hline Yellow or indigenous & 2 & 0.8 & - & - & 2 & 0.8 & - & - \\
\hline \multicolumn{9}{|l|}{ Religion } \\
\hline Catholic & 86 & 34.5 & 25 & 10.0 & 10 & 4.0 & 3 & 1.2 \\
\hline Evangelical & 68 & 27.3 & 21 & 8.4 & 6 & 2.4 & 1 & 0.4 \\
\hline Others & 8 & 3.2 & 3 & 1.2 & 1 & 0.4 & 0 & 0.0 \\
\hline No religion & 9 & 3.6 & 4 & 1.6 & 2 & 0.8 & 2 & 0.8 \\
\hline \multicolumn{9}{|l|}{ Employment } \\
\hline Employed & 73 & 29.2 & 19 & 7.6 & 8 & 3.2 & 2 & 0.8 \\
\hline Unemployed or looking for a job & 98 & 39.2 & 35 & 14.0 & 11 & 4.4 & 4 & 1.6 \\
\hline Retired & - & - & - & - & - & - & - & - \\
\hline \multicolumn{9}{|l|}{ Marital status } \\
\hline Married/stable union & 141 & 56.4 & 44 & 17.6 & 16 & 6.4 & 4 & 1.6 \\
\hline Single/divorced & 30 & 11.6 & 10 & 4.0 & 3 & 1.2 & 2 & 0.8 \\
\hline Widowed & - & - & - & - & - & - & - & - \\
\hline \multicolumn{9}{|l|}{ Family income (minimum wage) } \\
\hline Up to 1 & 38 & 15.2 & 13 & 5.2 & 7 & 2.8 & 1 & 0.4 \\
\hline $1-3$ & 98 & 39.2 & 33 & 13.2 & 9 & 3.6 & 3 & 1.2 \\
\hline Over 3 & 35 & 14.0 & 8 & 3.2 & 3 & 1.2 & 2 & 0.8 \\
\hline \multicolumn{9}{|l|}{ Type of childbirth } \\
\hline Cesarean section & 83 & 33.2 & 36 & 14.4 & 10 & 4.0 & 4 & 1.6 \\
\hline Vaginal & 88 & 35.2 & 18 & 7.2 & 9 & 3.6 & 2 & 0.8 \\
\hline \multicolumn{9}{|l|}{ Planning } \\
\hline Yes & 99 & 39.6 & 25 & 10.0 & 10 & 4.0 & 0 & 0.0 \\
\hline No & 72 & 28.8 & 29 & 11.6 & 9 & 3.6 & 6 & 2.4 \\
\hline \multicolumn{9}{|l|}{ Family support } \\
\hline Much support & 160 & 64.0 & 51 & 20.4 & 16 & 6.4 & 3 & 1.2 \\
\hline Little support & 11 & 4.4 & 3 & 1.2 & 3 & 1.2 & 3 & 1.2 \\
\hline \multicolumn{9}{|l|}{ Father support } \\
\hline Much support & 158 & 63.2 & 50 & 20.0 & 19 & 7.6 & 6 & 2.4 \\
\hline Little support & 13 & 5.2 & 4 & 1.6 & - & - & - & - \\
\hline \multicolumn{9}{|l|}{ Interrupted pregnancy } \\
\hline Yes & 1 & 0.4 & 1 & 0.4 & - & - & - & - \\
\hline No & 170 & 68.0 & 53 & 21.2 & 19 & 7.6 & 6 & 2.4 \\
\hline \multicolumn{9}{|l|}{ Preference of the child's sex } \\
\hline Boy & 17 & 6,8 & 7 & 2.8 & 4 & 1.6 & - & - \\
\hline Girl & 29 & 11.6 & 5 & 2.0 & 3 & 1.2 & 2 & 0.8 \\
\hline No preference & 125 & 50.0 & 42 & 16.8 & 12 & 4.8 & 4 & 1.6 \\
\hline Total & 171 & 68.4 & 54 & 21.6 & 19 & 7.6 & 6 & 2.4 \\
\hline
\end{tabular}

BAI= Beck Anxiety Inventory. 
association between severe anxiety and little support from the father/having interrupted the pregnancy in the evaluation of the variables related to pregnancy. As displayed in Figure 2, the main vectors (BAI_1 = minimum degree of anxiety, BAI_2 = mild anxiety, BAI_3 = moderate anxiety and BAI_4 = severe anxiety) were associated with one of the vectors of race in the sociodemographic variables and the father's support/interrupted pregnancy in the variables related to pregnancy.

\section{Discussion}

In the current study, we found prevalence of depression and anxiety at important levels (moderate to severe) below the parameters found in other studies. 15,16

The prevalence data for depression and anxiety in postpartum women is quite discrepant, varying from $7.2 \%$ to $39.4 \% .15,16$ This variability between the frequencies of depression and anxiety could be attributed to the heterogeneity of the sample,

\section{Figure 1}

Multiple correspondence analysis between sociodemographic variables/health conditions and depression in puerperal women in the BDI classification. Ponta Grossa, Paraná; 2017.
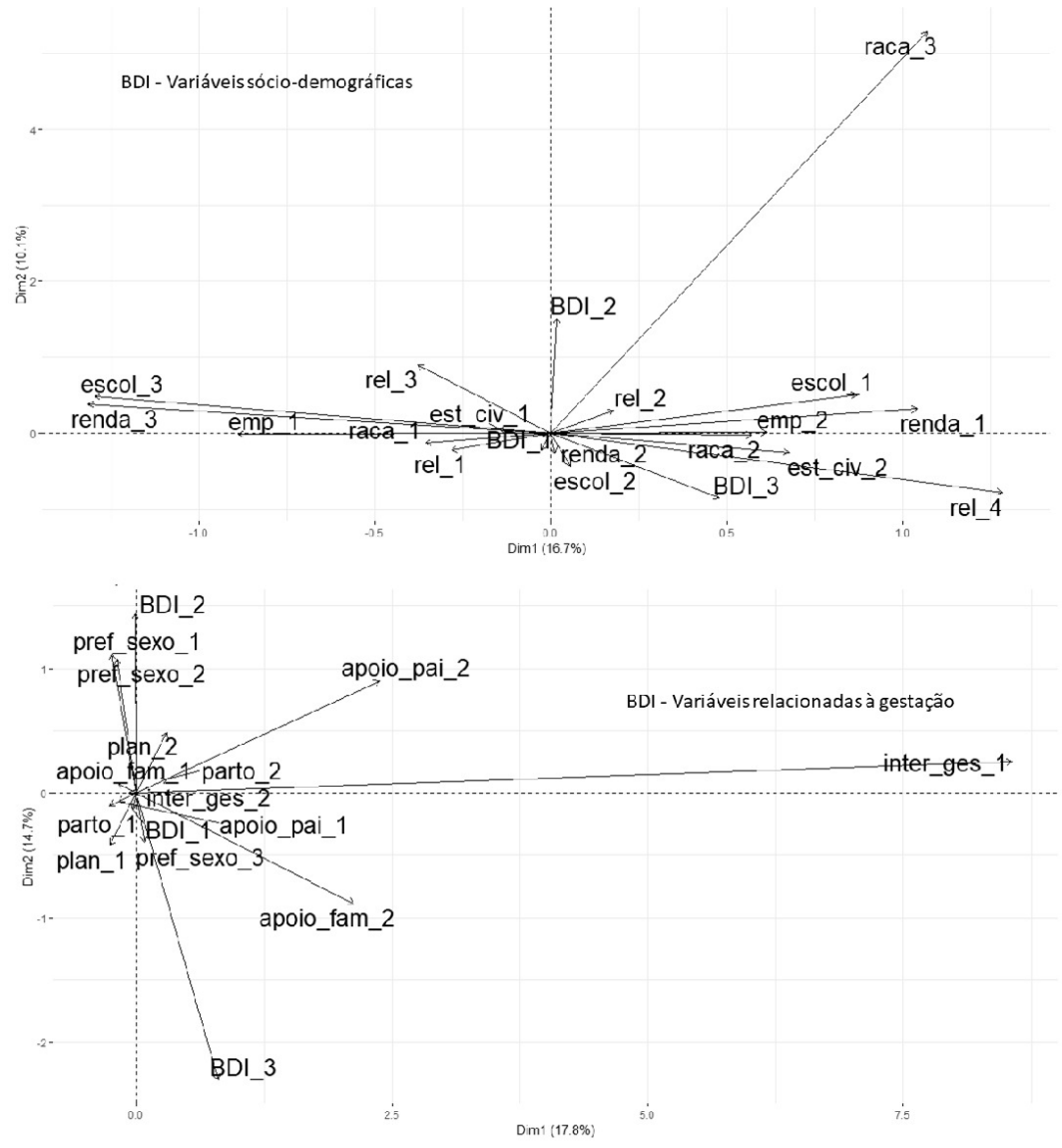

Captions: Variáveis sociodemográficas =Sociodemographic variables; raça = race; escol = schooling; renda = income; emp = employment; rel = religion; est_civ = marital status; Variáveis relacionadas à gestação = variables related to pregnancy; pre_sexo = preference of the child's sex; plan_= planning; apoio_fam = family support; apoio_pai = father support; inter_gest $=$ interrupted pregancy; parto = childbirth. 
Multiple correspondence analysis between sociodemographic variables/health conditions and anxiety in puerperal women in the BAl classification. Ponta Grossa, Paraná; 2017.
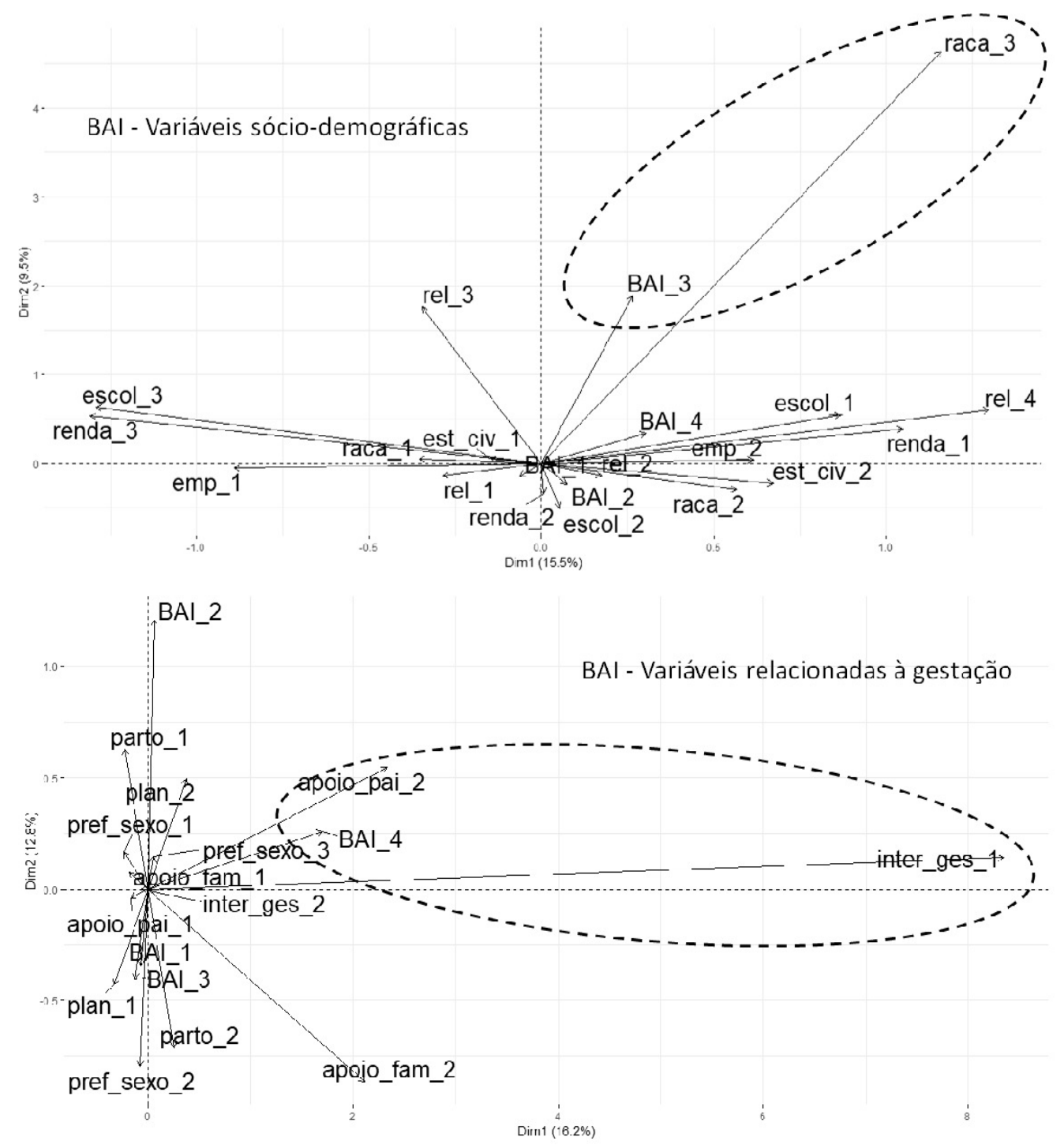

Captions: Variáveis sociodemográficas =Sociodemographic variables; raça = race; escol_ = schooling; renda = income; $\mathrm{emp}_{-}=$employment; rel = religion; est_civ = marital status; Variáveis relacionadas à gestação = variables related to pregnancy; pre_sexo $=$ preference of the child's sex; plan_= planning; apoio_fam = family support; apoio_pai $=$ father support; inter_gest $=$ interrupted pregancy; parto $=$ childbirth .

economic and cultural differences, as well as the various methods, evaluation scales and criteria, in addition to the difficulty of gathering reliable data.

Nevertheless, even with intense discrepancies about the prevalence of anxiety and depression in the postpartum period, it is certain that women require special attention at this stage of life on these conditions. In this period, women are more prone to develop psychological disorders.17-19 When becoming a mother, there is an important life transi- 
tion that requires adaptation to changes, new parents are required, social activities are modified or left in the background, sociocultural, family and personal demands take place, there are transformations in the hormonal, physical and emotional levels, conditions that favor emotional instability, which can generate anxiety and depression to a greater or lesser degree. ${ }^{17-21}$

Psychiatric disorders predispose to several negative repercussions on the patient, the child and the family's relationships, in the short, medium and long term.1,17,18,21 For women, postpartum depression can be perpetuated for several years, besides increasing the chances of other depressive conditions. $17,18,21$ Furthermore, the relationship with the child is also damaged and can negatively influence breastfeeding, 15,18 the mother's ability to respond to the demand involved in the care, the capacity for positive engagement and emotional contact with the baby. 17 The impact on children is also significant. Besides the aforementioned conditions, they may have difficulties in emotional and behavioral developments, as well as delays in cognitive development and weight gain. 1,17,22 In addition, depressive feelings are capable of altering a woman's self-perception and triggering conflicts in her family relationships. 21

Unlike what was found in the literature, depression in the women investigated in this study was not associated with any sociodemographic variable or those related to childbirth, 17,19,20,22,23,24 a condition that could be linked to the use of a more robust method of analysis (BDI and BAI classifications), different from what is commonly used in the literature. Nonetheless, there is also no consensus in the literature, but the main risk factors cited are: being single, occurrence of postpartum dysphoria, depressive and anxiety symptoms during pregnancy, history of depression, stressful life events during pregnancy, medical complications in the postpartum period and lack of social support. 17,19,20,22,23,24

As for anxiety at high levels, in this study, there was an association with skin color, little father support and having to interrupt the pregnancy. The higher anxiety of yellow/indigenous women, to the detriment of white women, can be explained by the reflection of this racial inequality in the various dimensions of social life existing and well consolidated in Brazil. Socially less favored segments, including black,mixed skin color, and indigenous people, have higher levels of illness and death from preventable causes, less access to and the use of health services, higher levels of maternal mortality, a higher risk of having inadequate prenatal care and a worse gradient of healthcare throughout the pregnancy and puerperal cycle. 25

Lack of social support, especially from the father, stood out as a predisposing factor for anxiety. Studies agree with the current finding, inferring that help and emotional support in postnatal care are protective factors. 1,17,24 The fact of having help in this process of constructing in being a mother, i.e., these new roles and skills that motherhood demands, mitigates feelings of fear and insecurity, as well as of guilt and incapacity. 1,17,21,22 If this support is not sufficient, the mother-baby bond may be hindered, and may be non-existent or exacerbated, causing impacting symptoms in the couples' lives and their children. ${ }^{1}$

Beltrami et al. ${ }^{1}$ study found that mothers with spouse support were those with minimum levels of anxiety. On the other hand, in the case of single mothers or mothers without a partner, there was a positive association with the presence of anxiety, since these women were really alone and without any support to care for their children. Therefore, family support has a great weight in the processes of maintaining mental health and coping with stressful situations, in addition to the adequacy of maternal behaviors towards children. 24

The relationship of anxiety with the fact of having interrupted pregnancy can be justified by the greater fragility in which the woman finds herself by having experienced significant stressful conditions, ${ }^{20}$ such as death, during previous pregnancies. There is an assumption that these abortions can lead to adverse psychological consequences, and women can externalize the past childbirth experience in different ways. The mother may have excessive concern in this new phase of life about the baby's health and development, the possibility of loss and the prospects for her future life condition, associated with a sense of susceptibility and helplessness, and these can worsen clinical scenario of anxiety. 21

In view of the above, it is important that health managers invest in maternal mental healthcare actions, throughout the pregnancy and puerperal period, that meet the recognition of the individual and collective risk factors, in order to enable early diagnosis and implement mechanisms to prevent, protect, treat, recover and maintain women's mental health, thus ensuring quality of life for these women and their relatives.

In this line of reasoning, the incorporation of a mental health professional with the patients at risk, as well as the training of health teams that assist prenatal, childbirth and puerperium for the adequate management and support patients in this delicate 
moment, would be a valuable help to avoid the negative impacts of these disorders in both mothers and children's lives. 20

This cross-sectional study design does not allow us to establish causal inferences between anxiety and postpartum depression and the studied sociodemographic/obstetric variables. Furthermore, we cannot infer whether the level of anxiety and depression was a cause or consequence of the studied explanatory variables. It is also worth underlining that the current study used two self-evaluation scales and not psychiatric criteria to classify depression and anxiety. Nevertheless, the limitations pointed out do not demerit the importance of the study in disseminating knowledge of these diseases in puerperal women.

We conclude that the prevalence rates of depression and anxiety at important levels (moderate to severe) found in the investigated puerperal women were below the parameters found in other studies.

\section{References}

1. Beltrami L, De Moraes AB, De Souza APR. Ansiedade materna puerperal e risco para o desenvolvimento infantil. Disturb Comun. 2013; 25 (2): 229-39.

2. De Oliveira MJM, Dunningham W. Prevalência e fatores de risco relacionados a depressão pós-parto em salvador. Rev Bras Neurol Psiquiatr. 2015; 19 (2): 72-83.

3. Abelha L. Depressão, uma questão de saúde pública. [Editorial] Cad Saúde Coletiva. 2014; 22 (3): 223.

4. Ruschi GEC, Sun SY, Mattar R, Filho AC, Zandonade E, de Lima VJ. Aspectos epidemiológicos da depressão pós-parto em amostra brasileira. Rev Psiquiatr do Rio Gd do Sul. 2007; 29 (3): 274-80.

5. Brito CNO, Alves SV, Ludermir AB, de Araújo TVB. Depressão pós-parto entre mulheres com gravidez não pretendida. Rev Saúde Pública. 2015; 49 (33): 1-9.

6. Greinert BRM, Milani RG. Depressão Pós-Parto: Uma Compreensão Psicossocial. Psicol Teor Prát. 2015; 17 (1): 26-36.

7. Angelo RCO, Sabino LF, Schwingel PA, Lima APO, Zambaldi CF, Cantilino A, et al. Pain and associated factors in depressed and non depressed puerperal women. Rev Dor. 2014; 15 (2): 100-6.

8. Cantilino A, Zambaldi CF, Sougey EB, Rennó Jr J. Transtornos psiquiátricos no pós-parto. Rev Psiquiatr Clin. 2010; 37 (6): 788-294.

9. Marques L de C, Silva WRV, Lima VP, Nunes JT, Ferreira AGN, Fernandes MN de F. Saúde mental materna: rastreando os riscos causadores da depressão pós-parto. Jounal Heal NPEPS. 2016; 1 (2): 145-59.

10. Arrais AR, Araujo TC, Ferreira C. Pré-Natal Psicológico: perspectivas para atuação do psicólogo em saúde materna no Brasil. Rev Soc Bras Psicol Hosp. 2016; 19 (1): 103-16.
This condition does not exempt the responsibility of managers to have a cautious look about the theme and invest in strategies that further mitigate these conditions, since their impact on mothers, children and family lives is quite significant. There was no association between demographic and health conditions with postpartum depression; however, regarding anxiety, the yellow/indigenous skin color, the lack of paternal support and the interruption of previous pregnancies were associated with more advanced anxiety conditions.

\section{Authors' contribution}

The authors contributed in all stages: planning the study, coordinating the application of the collection instruments, analyzing the data and writing the article. All authors approved the final version of the article.
11. Gomes-Oliveira MH, Gorenstein C, Neto FL, Andrade LH, Wang YP. Validation of the Brazilian Portuguese Version of the Beck Depression Inventory-II in a community sample. Rev Bras Psiquiatr. 2012; 34 (4): 389-94.

12. Greenacre MJ. Correspondence analysis in practice. 2 ed. Chapman \& Hall/CRC, editor. Boca Raton; 2007. 280 p.

13. The R Core Team. R: A language and environment for statistical computing [Internet]. R Foundation for Statistical Computing, editor. Viena, Austria; 2017. Available from: http://www.r-project.org/

14. Greenacre M, Nenadić O. Correspondence Analysis in R, with Two- and Three-dimensional Graphics: The ca Package. J Stat Softw. 2007; 20 (3): 1-13.

15. Faisal-Cury A, Menezes PR. Ansiedade no puerpério: prevalência e fatores de risco. Rev Bras Ginecol Obstet. 2006; 28 (3): 171-8.

16. Silva M de AP, Demitto M, Agnolo C, Torres M, Carvalho $\mathrm{M}$, Pelloso S. Tristeza materna em puérperas e fatores associados. Rev Port Enferm Saúde Ment. 2017; 18 (18): 8-13.

17. Figueira PG, Diniz LM, Filho HC da S. Características demográficas e psicossociais associadas à depressão pósparto em uma amostra de Belo Horizonte. Rev Psiquiatr Rio Gd Sul. 2011; 33 (2): 71-5.

18. Abuchaim E de SV, Caldeira NT, Di Lucca MM, Varela M, Silva IA. Depressão pós-parto e autoeficácia materna para amamentar: prevalência e associação. Acta Paul Enferm. 2017; 29 (6): 664-70.

19. Poles MM, Carvalheira APP, Carvalhaes MA de BL, Parada CMG de L. Sintomas depressivos maternos no puerpério imediato: fatores associados. Acta Paul Enferm. 2018; 31 (4): 351-8. 
20. Hartmann JM, Mendoza-Sassi RA, Cesar JA. Depressão entre puérperas: prevalência e fatores associados. Cad Saúde Pública. 2017; 33 (9): 1-10.

21. De Melo, Synara Barbosa Jordão RRR, Guimarães, Fernanda Jorge Perrellii JGA, Cantilino A, Sougey EB. Sintomas depressivos em puérperas atendidas em Unidades de Saúde da Família. Rev Bras Saúde Matern Infant. 2018; 18 (1): 171-7

22. Gonçalves APAA, Pereira P de S, Oliveira V de C, Gasparino R. Reconhecendo e intervindo na depressão pósparto. Rev Saúde Foco. 2018; (10): 264-8.

23. Zaconeta AM, De queiroz IFB de, Amato AA, Da motta LDC, Casulari LA. Depression with postpartum onset: a prospective cohort study in women undergoing elective cesarean section in Brasilia, Brazil. Rev Bras Ginecol Obstet. 2013; 35 (3): 130-5.

Received on May 27, 2019

Final version presented on June 1, 2021

Approved on August 25, 2021
24. Alfaia RDM, Reis LR, Magalhães MM. Uso da Escala de Edinburgh pelo enfermeiro na identificação da depressão pós parto: revisão integrativa da literatura. Rev Ciênc Soc. 2016; 1 (1): 1-19.

25. Leal M do C, da Gama SGN, Pereira APE, Pacheco VE, Do Carmo CN, Santos RV. A cor da dor: iniquidades raciais na atenção pré-natal e ao parto no Brasil. Cad Saúde Coletiva. 2017;33 (Supl.1): 1-17. 